\title{
Reporting Dirt and Disease: Child Ill-Health in Seventeenth- and Eighteenth-Century England
}

\section{Alysa Levene and Kevin Siena}

Poor bodies were both worrying and threatening in the eighteenth century. Medical depictions of poverty in discussions of contagious diseases presented it as degrading the human constitution with dangerous ramifications for pathology. High levels of infant and child mortality also forced reflection about the seemingly precarious health of society's youngest. Thus the poor and children were each in their own ways portrayed as prone to illness and contagion in the eighteenth century. What, then, of poor children? Were they inherently sickly? The issue is not so simple for when the issues of poverty and childhood conjoined one encounters mixed messages. On the one hand, poor children were poor. In theory they presented similar contagious risks to those posed by their parents. And yet, certain elements that commonly coloured medical narratives about poverty were either absent in discussions of children or else deployed differently with different effects. Ambiguity thus characterises medical narratives on poor children, whether because discussions of children frequently lacked the heavy moralizing that so often characterised commentaries on the poor, or because different agents crafted such narratives in different contexts and with different concerns. This article will compare narratives found in medical treatises that sought to explain the causes of disease with a quite different viewpoint created by the authorities charged with the actual bodies of poor young children. ${ }^{1}$

If, as cultural anthropologists argue, narratives give shape and meaning to human experience (Mattingly and Garro 1-5), then an exploration of how various commentators made their claims about poverty, age and sickness can shed light on their deeper concerns and assumptions, for example, about social order, governance and the state of the population. Doctors facing the possibility of epidemics were primarily concerned with identifying sources of infection. Thus they told tales, whether expressed as outbreak narratives or metaphorically rich medical theories, that emphasised the role of poverty and filth. The possibility that poor children might be inherently sickly was a by-product of narratives that emphasised heredity causes of disease, and at least one high profile example took these trends to their logical conclusion presenting sick children as a significant public health threat. However, men who were actually responsible for poor children addressed issues of health rather differently, being primarily concerned with reacting to the realities of spots, itches and fevers and how best to contain them. On the one hand, this article argues for differentiating between abstract theorists and pragmatists on the ground. However, this difference found expression not only in the content of the claims being made but in the form of those claims as well, for these latter commentators crafted narratives that allowed little space for seeing poor children in ways implied by medical theory. When thinking about narratives about the sickness of child paupers therefore, evidence suggests that their health was increasingly noted and valued; their bodies increasingly observed; and their ill-health largely divorced, at least on the ground, from the wider discourses about heredity, corruption and poverty seen in the contemporary medical tracts. 


\section{Paupers and Children in Published Medical Treatises}

Studies of early modern or eighteenth-century theories of disease focus rarely on class. $^{2}$ This is unfortunate because seventeenth- and eighteenth-century doctors emphasised the social stations of the bodies they discussed. Scholarship has amply shown that those bodies were differently gendered. (Lacquer; Schiebinger; Stolberg). Whether one considers reproductive or nervous disorders the proclivity for particular diseases offered one of the more important means by which men's and women's bodies were distinguished (Houston; Martensen; Gilman et al.). And yet, as important as gender was in this regard, class, that oft-neglected sibling of a category, may have been even more pressing in early modern discussions of disease.

This bold claim hinges on the fact that it was class not gender that grounded theories about the most dangerous disease of them all, plague. Scholars of plague, especially Paul Slack, have stressed the links between poverty and pestilence. Here focus falls less on doctors' theories and more on the social dispersion of mortality rates (whereby the poor almost always dominated among plague deaths) or on how plague ordinances masked social policing (Slack 199-226, 252-253, 284-310 and 336337; Champion). Yet doctors trying to explain epidemics - especially the vital phenomenon that plague raged most fiercely in poor neighbourhoods - forged a coherent set of principles about plebeian bodies, one that informed narratives about class and disease for nearly two centuries.

Theories on why infectious diseases seemed to target the poor stressed the concept of predisposition. It followed from the mortality figures that the poor must be "predisposed," their bodies having some peculiar quality rendering them especially susceptible (Wear 281-286). That quality was putridity. Plague was believed to arise from putrid or corrupt matter, especially from sources of filth: "stincking sewers, channells, gutters, privies, sluttish corners, dunghils, and uncast ditches" (Bradwell 4). When such matter entered bodies it corrupted the humours, sparking the internal putrefaction that doctors agreed was the essence of plague. But not everyone died in epidemics so this must have occurred only in certain cases, prompting the question: which bodies were most dangerous? Doctors like the Oxford physician Steven Bradwell, author of the 1625 plague treatise A Watchman for the Pest, argued that those bodies whose fluids were already of putrid nature were plague's primary targets; their blood was apt to putrefy since it was already partially corrupt. By that logic he named those most susceptible:

Poore People, (by reason of their great want) living sluttishly, feeding nastily on offals, or the worst \& unholsomest meates; and many times too long lacking food altogether; have bothe their bodies much corrupted, and their Sprits exceedingly weakened: whereby they become (of all others) most subject to this Sicknesse. And therefore we see the Plague sweeps up such people in greatest heapes. (46)

The poor absorbed filth from their dirty environments and ingested it as low quality food. Importantly, impoverished bodies could generate plague even with no external infection. Mirroring longstanding warnings about pathogenesis from blocked menstruation, paupers' fluids were believed to reach deadly levels of putrefaction if they did not sweat out their impurities.

[T]hey are most apt, whose veins and vessels are full of grose humours and corrupt juices, the evil matter (being thicke, and therefore cannot breath out 
through the pores) increasth her putrefaction (by the heat within) unto the greater malignity, and so becometh Pestilent. (45-46)

We can read in Bradwell's treatise an attempt to make sense of the frightening phenomena he and his contemporaries faced in epidemics. As body counts mounted in poor neighbourhoods, men like Bradwell crafted stories in which they imagined the filth that surrounded paupers as necessarily having permeated the deepest inner reaches of their bodies. Bradwell transposes that filth inwardly and creates a narrative about stagnation and containment. The plebeian body becomes like a kind of prison; matter enters it but it cannot leave. But the body is also configured as a kind of improperly ventilated container. Lacking drainage for its "corrupt juices," the body becomes like a bottle stopped up for too long, its contents becoming rancid. With so many paupers dying in urban epidemics, the story becomes plausible to anyone observing the spread of diseases with some trepidation.

Versions of this theory provided key components in medical narratives highlighting the dangers of poor bodies throughout the seventeenth and eighteenth centuries. Pointing to food, physician Nathaniel Hodges argued that paupers' dietary practices "very much contribute to that Disposition of Body as made the pestilential Taint more easily take Place." (20,58-59) Such thinking was especially prominent during the panic of the early 1720s when plague ravaged Marseilles and threatened to make the short journey to Britain. It was even endorsed by physician Richard Mead, the leading authority on plague. Mead advised London officials to "immediately send skilful Physicians to Visit the Houses in the Neighbourhood, especially of the Poorer sort, among whom this Evil generally begins" (38).

Plague eventually receded as a focal point of concern, but that did little to diminish medical emphasis on the biohazard of poor bodies. By mid-century forms of fever presented the most frightening diseases linked to class, as Candace Ward's exploration of fever narratives in medical texts and novels shows (100-148). Although military physician John Pringle, the leading theorist on such fevers, wrote more than a century after Bradwell, his language was remarkably similar, suggesting that the narrative of the inherently putrid pauper was potently durable despite considerable theoretical developments within medicine:

[T] he internal predisposing cause, [is] namely a more than ordinary putrescent state of the blood [. . .] this disease caeteris paribus prevails mostly among such as are of a scorbutic (that is a putrid) habit, or among the poorer people, who from foul air, bad diet and nastiness are most liable to putrid diseases. (252)

When doctors like William Cullen warned that inadequate activity increased such putrescence they reiterated Bradwell's earlier warning about inadequate perspiration, a mainstream medical tenet by the mid-eighteenth century (Risse 150156). The idea's popularity and longevity owes much to its value for narratives pathologizing idleness, the cardinal sin of the early modern poor. Moralists forever presented idleness as the root of poverty, disorder and sin (Beier 4-7, 38, 165; Pugliatti 55-63). Doctors' comments about perspiration thus augmented narratives found in fiction or texts on welfare and crime that highlighted the dangers of laziness - the most famous of which must certainly be William Hogarth's series of engravings Industry and Idleness (1747) depicting the lives of two apprentices: the industrious Francis Goodchild, who works hard and becomes the Lord Mayor of London, and the 
lazy Tom Idle, who slides into crime and dies in a hangman's noose. Here the deeper cultural work of medical narratives becomes clearer, as medical theory becomes a vehicle for moral condemnation. The author of the New Discovery of Plague (1720) would seem to offer support to those theories of narrative that suggest that "narrators moralise the events they recount" (Mattingly and Garro 11). He attributed pathogenic predisposition to "careless, nasty idlers, who live always on the Fruits of Laziness, [and] the most loathsome Food" (New Discovery 27). Mead concurred, including "Beggars and Idle Persons" in his advice to keep the streets "clean from Filth, Carrion and all Manner of Nuisances" (43).

Nuisance diseases like skin infections are also instructive, not least because they presented major problems for children, as the next section discusses. The disease known as the Itch, for example was recognised as highly infectious, however, physicians like Thomas Spooner argued that, like plague or fever, it could also be generated anew by those with putrid blood. He drew on seventeenth-century medical luminary Thomas Willis who in 1684 had identified failure to perspire as one of its causes. Those "of a sedentary life" were prone to it because their humours were not properly "eventilated" and thus corrupted like swamp water. (156). An apothecary who quoted Willis added: "which is the true Reason, why the Poor are most obnoxious to Disasters of this Kind" (P. L. 26, 34). Physicians crafted outbreak narratives that share qualities with those described by Prescilla Wald about Typhoid Mary, in which infectious diseases spread frighteningly across class lines through vectors like domestic servants (68-113). ${ }^{3}$ Such anxiety was well captured in William Ellis' family health manual which recommended strip-search examinations of prospective employees to punctuate the narrative of a teenage servant who spread the Itch to respectable families:

At Gaddesden he lived about a month before he was found out, then discharged and went to another, and so on, till he thus mightily spread this horrid Disease in Hertfordshire, because they neither inquired his Character, nor search'd his Body; if they had done the last they had found his Legs grievously scabbed, for he kept the Itch out of his Hands by now and then anointing them. The Servant-maid was one that thus brought the Itch into my Family, for she was in as bad a Pickle as the Boy, having her Arms and Hands clear, but her Legs sadly scabbed. (262-63)

Ellis thus harnesses the threat of infection to concerns about the rootless and mobile working class, here portrayed as untrustworthy invaders corrupting the sacred family home. Like stories crafted about Typhoid Mary the following century, Ellis's tale plays on the hidden nature of contagion. The devious, nay sinister, quality of these servants lies in their attempts to deceive by anointing the visible parts of their bodies, their hands, so as to conceal their lesions. All the while underneath their clothing and by extension in their blood - lurks disease. In Ellis' narrative the lesions take centre stage, as they would in coming decades throughout medicine more generally, which saw the rise of pathological anatomy, a medical vision centred on identifying disease by morbid structural change (Foucault). Ellis thus embodies nascently a Foucauldian gaze, one that demands lesions be discovered, or because he advocated strip-searches, in this case literally un-covered.

The constitutional nature of many ailments associated with poverty - the belief that they rooted themselves in the blood - meant that they had the potential to be passed hereditarily. This presented another way for diseases to be presented as lurking 
within, and it marks a potentially major issue for thinking about poor children. Syphilis made the danger of congenital transmission obvious, but so too did other putrid diseases, such as scurvy, of which Charles II's physician Gideon Harvey proclaimed, "Infants oft bring [. . . ] Scorbutick Seminaries with them into the world" (8). However, it was not just that a diseased mother could impart her ailment to her fetus, rather sickly parents could also bestow their predisposition. Children of sick parents might be born ill, but they also might be born with a lurking quality that could lead them to become ill at some later date. As early as 1669 Thomas Coxe described how the vices of parents could have longstanding health effects, asking rhetorically:

What is more frequent than for weakly diseased Parents to be further tormented by seeing their Children labour under the same Infirmities; which are either rivitted into the Principles of their Constitution, or sucked in with their milk: from which dispositions they are hardly, if ever freed [?]. (9598)

Pathological predisposition could thus be fixed permanently: "rivitted" into the constitution from birth.

Eighteenth-century physicians like Richard Blackmore stressed the danger of such hereditary 'taints':

[T]he Internal or Cogenite Causes [of fever and plague] may be Interwoven and complicated with the material Principles of the Body at its first Formation, as the Seeds of many Distempers are [. . .] we may therefore conceive with Ease that sometimes the Principles of Malignant Fevers are combin'd and closely united with the Original Parts of the Blood, and are afterwards awaken'd, let loose and freed from their Imprisonment, by the Help of irregular Agitations and Conflicts, that arise in the Blood. (21-22)

Earlier narratives imagined filth or rotten food imprinting their malignant qualities on plebeian bodies. Here, however, parents' sins are visited upon their children, the elements of disease imagined as fusing with the basic building blocks of the child's body, in this case the blood. Using a metaphor drawn from the textile trades, Blackmore depicts disease "interwoven" into the child's elemental fabric. His narrative is actually a smorgasbord of mixed metaphors. Disease is woven like a fabric, but it is planted like a "seed." It slumbers until "awakened," while simultaneously incarcerated until freed from "imprisonment." The addition of hereditary principles represented a deeper way in which class, not unlike race, could be conceived in increasingly essential terms, rooted in the blood and passed on at birth. Yet, as scholars who have explored the history of heredity have argued such formulations did not yet express the hard hereditarian theories witnessed in the nineteenth century (Müller-Wille and Rheinberger). Biology was not yet destiny in this regard. Poor children might carry the taint of their parents, yet it might never ignite into disease. To use Blackmore's metaphors, the seed might never grow, the slumbering monster might never awaken, the prisoner might never break free.

Poor children thus had the potential to present quite dangerous bodies. Daniel Defoe's core strategy in his Due Preparations for the Plague (1722) - calling for the evacuation of London's pauper children - is telling in this regard. Defoe's Journal of the Plague Year was, of course, the better known work. Weaving together elements of 
history, journalism and the novel it famously complicates genres and contains much rich material for the study of medical narratives. However, the Due Preparations, published within months of the Journal, assumes the more didactic tone of the physician's treatise, although Defoe was no doctor. Calling impoverished bodies "the Fuel which the Fire of the Pestilence generally Feeds upon" (22), Defoe argued that it logically followed to rid the city of them when plague threatened. Along with felons and pensioners, Defoe listed category after category of poor children who must leave: children in orphanages, hospitals, schools, as well as "all the Children of the Poor, as are not in Condition to maintain them" (19-22). Defoe's plan crafts an outbreaknarrative in advance. While plague threatened from Marseilles, he wrote two books: one (The Journal) a depiction of the worst-case scenario employing the literary conventions of fiction and history, the other (The Due Preparations) a strident warning of what must be done to prepare. In this latter work he itemised London's most dangerous bodies, and poor children dominated the list. Defoe summarised the advantages of his scheme:

Tho' there would still be many Thousands of Inhabitants left, yet they would live at large, be unincumber'd with Poor, and with Children, and with all the Stench and Filth that attend those who want Conveniencies, and who would in such a Calamity only serve to Infect one another, and strengthen the Contagion in general (23).

It is intriguing that while doctors could have followed Defoe in portraying poor children as health risks, they did so infrequently. One must consider the context of Defoe's text; written during an epidemic panic it seems that theories of the pathogenic plebeian body reached a logical conclusion and coloured the depiction of poor children. However, narratives written in other contexts and in different genres often did not follow suit. Moreover, because medical narratives on the putrid plebeian body frequently offered moralizing condemnations thinly masked in medical jargon, it was hardly straightforward to apply such claims to children who were not typically regarded as blameworthy and on whom responsibility for filth and disease was harder to pin. Finally, plague never came to London in 1722, so Defoe's children were, to a great extent, fictions. His plan never came to fruition and thus remained merely an apocalyptic figment of his famously creative imagination. People encountering poor children in the flesh often told different stories.

\section{Sickness Narratives in Practice: London's Pauper Children}

It is clear from the foregoing that medical narratives about poor bodies called on a range of reference points to explain sickness, from heredity, to environment, to inherent 'putridity.' The evidence suggested that there was potential space for the bodies of poor children in these models because of the possibility of inheriting tainted blood from parents. This section will test how far these theories were referenced by those actually dealing with the bodies of the young poor, in this case, metropolitan parish officers inspecting the care of their pauper children being nursed outside London.

This system of paid nursing was legally formalised in 1767 at the instigation of social reformer and philanthropist Jonas Hanway. The law (the Act for the Better Protection of Parish Poor Children, otherwise known as 'Hanway's Act') applied only to the parishes covered by the London Bills of Mortality, although some larger parishes lying outside its remit adopted its terms voluntarily. The plan was modelled 
on the London Foundling Hospital's system and mandated that young children would be sent out for care and regularly inspected (Levene). Not all parishes were so assiduous in inspecting them - or at least keeping good records that they were doing so - but those that did leave a valuable record of the ways that childcare was being managed, including episodes of sickness. And while they do not offer either patientnarratives in their purest form, in that they were not created by the children themselves, or the more classic form of narrative which is mediated by the practitioner, what they do provide is something quite new and quite different from the perspective typically found in doctors' published treatises. ${ }^{4}$ Thus they broaden the historical perspective on children, poverty and illness by allowing a different set of voices to speak.

The reasons that this system were put in place reveal quite a different set of concerns than those voiced by the doctors cited above, and provide a potentially competing framework for understanding what the bodies of pauper children represented for the authorities. The primary impetus came from empirical studies of infant mortality in London workhouses carried out by Jonas Hanway in the early 1760s. These had revealed appallingly high death rates of infants who were basically left to languish without proper care. Hanway was also an active governor at the London Foundling Hospital and so he naturally turned to the system of paid nursing in the countryside which had been used successfully there. However, Hanway's interest formed part of a wider focus on the strength of the nation which came about because of fears of population decline and the quantification of national productivity; a model in which the physical well-being of the working classes was particularly prised. Children's bodies were particularly important to this vision of national strength as they carried the potential for future greatness. Early death, and perhaps to an even greater degree, chronic and constitutional sickliness, represented a national drain, especially considering the monies invested in pauper children by the parish. Many of the well-known pamphleteers of the second half of the century, including Hanway, Jeremy Bentham and Frederic Morton Eden, quantified the cost to the nation of every working class child whose adult labour was lost through early death. In Hanway's words the poor rates were thus "the instruments of preserving a vast number of subjects, particularly children, who are so much more valuable than the aged" (3). In these narratives poor children were framed not as public health risks but as vital national resources. The increased interest in doctoring and health was thus matched with a focus on economic value, profit and loss, which made the vitality of the young poor particularly potent.

The rest of this section will consider how far the sorts of narratives identified in the medical discourses were played out in the care and treatment of metropolitan pauper children. In particular, it will suggest that the poor law officers concerned with the daily treatment of child paupers crafted narratives in which pragmatic concerns outweighed more theoretical ideas about hereditability of disease or constitution, and that where heredity was a factor, it was more commonly linked to moral behaviour than disease. However, the intentions of the 1767 Act can also be read as an attempt to divorce children from the physical and familial environment in which they had been born, and this provides an important part of the framework for thinking about disease among the poor.

The new system of nursing for London's pauper children affected from tens to hundreds of children every year across almost every parish in London. We are fortunate that several parishes set up committees of 'Guardians of the Infant Poor' in the wake of the 1767 Act to inspect their nurse-children, and their minutes contain 
material which reveal the ways that the bodies of pauper children were being described and narrated. While they do not record the words or actions of the children themselves (this would be highly unusual for this period) they are highly revealing of narratives about sickness, robustness and poverty from the perspective of their caregivers and their supervisors. And while the regularity and comprehensiveness of inspections varied considerably, from regular visits out to the country parishes to a note of reports sent in from local representatives, there was a fair amount of consistency in what matters were deemed worthy of notice: most commonly, health, diet, clothing, the cleanliness of the children and the nurses' homes, and education. Together these provide a framework for thinking about the ways that narratives on pauper health were being created. The most high profile themes will be discussed in turn.

Consider culpability. We have seen that paupers attracted some degree of blame for their poor health in the medical literature, for example, by awakening a tendency to putridity and disease via poor diet or immorality. This is never seen in the documents on pauper children; instead if culpability is attributed anywhere it is to the nurse. For example, the St Botolph Aldgate Guardians recorded in February 1806 that they were dissatisfied with Mrs Hannah Meredith - who was caring for seven parish children - because she was "very dirty in her person and [that] her house [was] so filthy as makes it necessary that she should have a severe reprimand." Things were deemed to be much improved on their next visit. However, on this occasion another nurse, Ann Hart, was singled out for blame, this time connected to a child's illness: "her beds very dirty and bad, her cupboard not sweet, children cloaths in bad Condition, and the Children dirty and Indisposed with the Itch" (St Botolph Aldgate Guardians' Visiting Book 4 February 1806 and 16 June 1806). That ill-health is here being so firmly connected with poor conditions and dirt, and that the nurse is blamed for the children's indisposition, suggests that the children themselves were not thought to be harbouring the predisposition - even for the 'itch' which featured prominently in medical narratives about the pauper body. It is of course worth pointing out that inspectors' reports represent a kind of official narrative, one that leaves no room for possible counter narratives, like, for example, ones by the nurses themselves. There is tantalizingly little known about the status and conditions of these women, but nursing for the parish was not a sought-after employment compared with childcare for private families. It is likely that they were not particularly well off, though that is not to say that their homes and housekeeping were substandard. Certainly the cases of poor conditions were reported as anomalous.

The culpability of nurses in spreading diseases had a long pedigree. Doctors had long recommended that parents take especial note of the health, physical robustness and character of potential wet-nurses lest they corrupt or infect their charges. The stress on inspection under Hanway's 1767 Act was specifically intended to banish the "indigent, filthy, or decrepit women" who had acted as parish nurses previously, who scrimped on provisions because they were paid so poorly, and whose neglect and ill treatment of their charges led to "the State [being] wounded in its vital parts" (Hanway, 43). Another commentator, Lewis Mansey made this link even clearer in his work The Practical Physician (1800):

It is no wonder [. . .] that infants are often affected with ulcers, the itch, scald heads and other cutaneous disorders, by nurses whose diet is irregular; or, if the nurses are afflicted with the venereal disease, that the children 
contract the same; or are contaminated with pustles and eruptions, and a thousand other infirmities. (405)

This sounds very much like the mistrustfulness of the bodies of the poor drawn out in the previous section - but also by implication a lack of such preconceptions attached to the pauper children. Indeed, when Hanway reflected on the spread of diseases including the itch in the workhouse serving St. George's Middlesex, he crafted a narrative that makes it impossible to see the children as responsible in any way. They can only be victims when he says: "It is true that man hath but a short time to live and is cut down like a flower; but these poor infants were mowed down like grass" (42). Moreover, the reporting of infectious skin conditions is often very matter of fact about their ubiquity among children and there is no suggestion that there is a moral judgement being attached to their appearance beyond that attributed to some of the nurses. As Spooner, wrote in his A Short Account of the Itch: the Itch is communicated [. . .] by means of lying in strange Beds, by Children of different families playing together, or by Servant Maids or Nurses \&c. that have had this loathsome Disease, and come into Families before they are perfectly cured of it" (34). Here, one pathway for contagion is presented as a natural, and therefore innocent, part of childhood; notably it is maids and nurses who are singled out as possible vectors.

However, in other cases, nurses were praised for their care of young children in sickness. After all, inspectors were concerned to police parish employees. Thus narratives admonishing faulty nurses sat aside others that recognised excellent care. Mrs Page, for example, the nurse of six parish children from St Dunstan in the West, was given $2 \mathrm{~s} 6 \mathrm{~d}$ and $1 \mathrm{~s}$ for her servant at one visit "from a Motive that she had taken Care of the Children and would continue to do so [. . .] the most part having been down with the Hooping Cough" (St Dunstan in the West Committee of the Guardians of Poor Children 10 July 1793). Here children's illness is framed not as the nurse's fault, but as a factor rendering her work more difficult and therefore laudatory. Even when one of the children died, the apothecary reported that nothing more could have been done. The London Foundling Hospital provides similar reports. One inspector reported to the hospital in 1759 that:

Ann Rosewell [a nurse] has had the misfortune of losing her last Child soon after she brought it home; it was so ill when given her that every body expected it wou'd have dy'd upon the Road [. . . She really is a good nurse, $\&$ will do justice by the Children, the Hospital entrusts her wth, she was very much dispirited wth losing the Child so soon, but hopes the Governors wont have a bad Opinion of her as it was so ill when deliver'd to her, \& if they'll be good as to let her have another, she'll take all the Care imaginable of it. (Foundling Hospital Correspondence 23 April 1759)

Here the inspector's narrative employs the nurse's emotional state - her sadness at the child's death - to evoke quasi-maternal qualities, in an effort to convince that she continue to be entrusted with surrogate motherly duties in the future. The child's illness (mentioned twice) serves not to warn about contagion but to exonerate the nurse of any guilt, employing the narrative structure of the hopeless case; nothing could be done. As a story, it is a tragedy, but one in which there can be no blame.

Even when children carried disease into nurses' households it was often not the nature of their bodies which was discussed. Rather, parish officers accepted 
responsibility (probably because keeping the nurses' confidence was so important for the functioning of the system), and characterised the children's illness as a ubiquitous part of youth. St Sepulchre Holborn ordered that no children be sent out to nurses in December 1771 "in Consideration that the Small-pox now Rages in the Workhouse," for example (St Sepulchre Holborn Minutes of the Meetings of the Guardians of the Parish Poor 20 Dec. 1771). Instead of putridity or heredity, therefore, parish officers more often called on the natural age-distribution of disease as an explanation for sickness. When Hanway addressed the issue he actually employed the medical language of heredity, warning overseers to be on the lookout for children with "venereal taints" who might infect nurses. However, he immediately downplays the risk, assuring them this "but very rarely happens" and notes that screening the infants would give parish officials "a title to examine also into the state of the health of nurses, that no child be hurt by any of them, which is by far the more probable case" (66). It is perhaps not surprising that parish officials did not debate the origins of illhealth in their charges in the way that doctors did given their quite different backgrounds, but there is no evidence that they dwelt on causes beyond occasional references to cleansing workhouses and isolating infectious cases. These men were much more concerned to treat disease when it appeared than to worry about possible hereditary taints. Perhaps by these later decades of the century and after the publication of many works on fevers in gaols, ships and prisons, the tendency for poor bodies to breed disease was simply accepted. The very ubiquity of transmission between children, however, suggests that physical contact did form a part of this narrative.

There is just one comment in the surviving records which suggests another framework for explaining disease in children, and this can also be connected to age rather than class: humoural theory. It was reported in the context of the discovery by visitors from St Dunstan in the West parish that many of their children had "scabby heads." They were interrupted in mid-lecture to the nurses by the local apothecary, who explained "that it did not arise for want of attention of Cleanliness but from Humours in the Blood to which Children of that Age were often very Subject" (St Dunstan in the West Committee of the Guardians of Poor Children 30 Sept. 1803). Humoural predisposition in children has recently received detailed attention by Hannah Newton, who points out how live a narrative it continued to be well into the early modern period, and how overarching a framework for the explanation of disease in children (31-62). This, then, could be a different form of predisposition to that outlined in the earlier section, but, tellingly, one which had little reference to class. Once again, children seem to have remained relatively free from the notion that they were responsible for their own health as far as discussions by officers 'on the ground' were concerned, and those officers crafted their narratives in ways geared towards stressing this point.

This finding can be linked to a lack of culpability attached to children generally within the context of discussions on poverty. The poor laws, which originated in the Tudor period, did have a firm emphasis on self-responsibility, but this was attached to able-bodied adults. The sick, the elderly and the young were all members of the "deserving poor," the validity of whose relief was much less problematic (Lees 52-60). The situation for children was complicated by the feeling that some adults bred fecklessly and so large families could in themselves be signals of moral taint. However, blame fell squarely on the parents rather than the children.

The environment of the nurses' homes also clearly informed views of disease among pauper children, as several foregoing quotations have shown. This was 
generally connected with dirty conditions and poor housekeeping rather than the sort of crowding and lack of sanitation implied in the medical literature. Again, this implies that a key element in the narratives about adult pauper disease - personal cleanliness - was not applicable to the young because they controlled neither the frequency of their washing nor their surroundings. However, this contrast raises an alternative view of environment which may be much more significant in the current case: the difference between London and the countryside.

The basic premise behind the move towards country nursing was that London was a poor environment for children, and especially so its workhouses which brought poor nursing care and a high risk of infection. While do not know whether a similar view was taken of the homes of the poor, certainly some medical treatises of the sort examined earlier cast them in a dangerous light. Consider bestselling physician William Buchan's narrative comparing working class homes to filthy prisons:

Nor are many of the holes, for we cannot call them houses, possessed by the poor in great towns much better than gaols. These low dirty habitations are the very lurking places of bad air and contagious diseases. Such as live in them seldom enjoy good health; and their children commonly die young. (58)

Nonetheless, the intentions behind the 1767 Act set the countryside up as a healthier place for the young than the capital; therefore the nurses' homes by definition offered a more benign environment for them. Like Defoe before him, Hanway (and also the London Foundling Hospital) made distinctions between the distances that different groups of children should be sent from London (babies and those without mothers should go the furthest), and later surveyed mortality among nurse children sent to different communities. (25-39, 78, 99-100) However, unlike Defoe, this seems to have been straightforwardly intended for the benefit of the children, rather than for the protection of Londoners. By the end of the century some of the larger parishes were operating houses in the countryside for their pauper children, which could be viewed within the same paradigm of confinement as was used for the mad and the refractory poor. However, in this case, there is little to suggest a reformatory role beyond a possible desire to remove them from their parents (Levene 91-106). In fact, it may say more about the logistics of childcare on a large scale than about either contagion or the transmission of moral values.

The question of heredity and family connections is the last of the major themes in the medical narratives about pauper bodies. Again, it remained uncommented on by parish officers, but that is not to say that it was unimportant. The risk of contagion posed by families struck by infection was certainly a live issue: the records for several provincial infirmaries show parishes sending whole families with the Itch, for example (Levene et al.). Even closer connections were made in the case of venereal diseases, which were known to be transmitted in utero. One of the most pressing concerns about this group of diseases was the possibility for a husband to infect an innocent wife and children (Dunlap, Stewart); another pathway of concern was the transmission between nurses and infants, as Hanway's earlier comments showed.

In a wider sense, however, heredity was important for parish officers, but in quite a different way from that imagined by medical authors. Writers on poverty and the poor law instead focused on the transmission of moral habits from parents to children, and the danger of poverty becoming inherited by the observation of bad behavior. This was one reason why poor children were seen to be worth investing in: 
if they could be educated in better ways they could be kept from falling on the poor rates later, and perhaps even act as a conduit for these teachings to travel back to their families. The short-lived Dispensary for the Infant Poor set up in the 1760s which apparently served many thousands of families also hoped that their teachings on childcare would improve the health of the whole family (Levene 143-4).

This aspect of heredity shares characteristics with the medical one: both had a moral aspect as well as a physical one, and both allowed for moral outlook to have an impact on the health and constitution. Lewis Mansey, quoted earlier warning about nurses infecting children, expressed a parallel concern about the nurse's moral impact, exemplifying the interconnected anxieties about physical and moral forms of contagion:

And since not only defects of the body, but of the mind also, are communicated by the depraved milk, it is certainly not uncommon for children, born of the best parents, sometimes to be corrupted with the worst morals. Thus I have known infants rendered drunkards, by sucking the milk of a nurse addicted to drinking. (405)

Parish officers did not overtly comment on either, but in the context of pressing financial concerns and the need to prioritise certain groups of the poor on the basis of need and likely chances of independence, it is likely that moral taint was more important than a latent medical or constitutional one. However, parish officers did not often enforce a separation between children and parents, implying that in neither case of heredity - moral nor physical - did this concern over-ride the natural rights of the family (or perhaps, the convenience of parents continuing to provide care). Parents were often able to get their children back after relatively short stays with nurses, and could usually choose to remain together even if this meant both leaving the workhouse. This was true even in cases where the parent's moral character was in some doubt, for example, in cases of drunkenness, homelessness or perceived fecklessness. While theories about class and predisposition may have played an important role in hardening theories of heredity in the nineteenth century, in the shorter term they seem to have had less influence on the actions of poor law authorities charged with the immediate material concerns of caring for sick children.

\section{Conclusions}

This article has shown both the fluidity of co-existing theories of disease among the poor, and a demarcation between the ways that this was projected onto the bodies of children and adults. In the case of pauper children these narratives largely failed to compete with pragmatic concerns about survival, and a much longer-held set of reference points about the deserving nature of poverty in childhood. While the bodies of adult paupers were worrying in general, those of children were viewed in quite a different context. There might have been more cross-over in ideas had there been more medical interest in the children of the poor: the published work on child health focused mainly on the higher echelons of society: although some authors who had experienced practice in hospitals and charities made passing reference to poor children, it was generally in the context of their greater physical robustness (see: Cadogan; Buchan). It was not until the final decades of the century that medical men started to observe the health of poor children in greater numbers, or visit their homes.

The primary narratives of ill-health used by doctors are therefore not reproduced in the documents generated by the inspectors of pauper children in the 
second half of the eighteenth century. Much of this is probably due to the different nature of the sources: the Guardians of Poor Children were rarely medical men, and their minutes were not constructed as reflective documents. Their concerns included finances, logistics, and even discipline. The problem of sick or potentially sick pauper children loomed large, but when they wrote parish officials were less likely to present such children as inherently contagious threats. Their narratives emphasised the value of protecting a valuable resource or else presented children as victims in order to admonish bad parents or nurses. One has to rely on actions to reveal intentions in a way which they do not with the medical sources. However, what these sources do show us is whether and how medical discourses were put into practice. What the practice suggests is that parish officers were very much concerned with simply dealing with ill-health, and that the ubiquity of contagion and infectious disease among children was a much more pressing and valid framework for explanation than taint, environment or behaviour. The types of ill health that they saw most frequently were not the fevers which so exercised medical authors, but instead the Itch, scabby heads, and diseases like smallpox, whooping cough and measles. For these, they had a much readier explanation to hand: the vulnerability of young children to diseases transmitted by contact. Furthermore, many of the alternative explanations called upon in the medical texts: personal behaviour, diet and cleanliness, were not applicable to children, either for practical reasons, or because they did not fit with the on-going model of the causes of pauperism. Children were simply not culpable for their condition in the same way that adults were. This is proven further in the fact that the only people held up for blame for the children's sickness were their adult caregivers.

The differences found between medical theory and the writings of welfare agents concern not just content but form as well. Physicians staring down the frightening spectre of epidemics were primarily concerned to identify, and thereby police, public health risks. They crafted their narratives accordingly, whether in case studies that take the form of the outbreak narrative or metaphorically rich theories that allowed them to speculate about what went transpired in the arteries and veins of the paupers who died by the thousands in epidemics. For these writers cause, and therefore culpability, was paramount. The high levels of mortality among paupers and children led Defoe to take this to a natural conclusion, metaphorically likening poor children's bodies to fuel for a fire, and calmly calling for their expulsion from the city in the name of public safety. Parish officials or children's advocates like Hanway, however, took an altogether different tack. Faced not with hypothetical tragedy, as Defoe was (for plague never came), but with the all too real tragedy of dead infants, they seem virtually incapable of seeing pauper children as culpable and yet they were simultaneously determined to pin blame somewhere. They structured their narratives to convey these impressions. This tendency may find one of its clearest expressions in the work of pauper children's great eighteenth-century champion, Jonas Hanway, in his Earnest Appeal. While he structured numerous arguments differently throughout the book, his most powerful strategy was to deploy a rhetorical technology that was becoming ever more common in enlightenment social science: the numerical chart. Page after page contain ledger lines and numbers conveying horrendous mortality rates. Comprised mainly of numerals rather than words, it is tempting to view them as the opposite of a narrative, even a kind of anti-narrative. However, this would be most misguided, for these charts tell stories, too. It is in Hanway's tables that his argument is made most forcefully. Reading them as narratives is potentially revealing for they express in dramatic terms what parochial inspectors' narratives also tried to convey. Pauper children, expressed here only as numbers, can bear no responsibility. They 
cannot infect. They cannot transgress. They cannot act, immorally or otherwise. They can merely die, in some cases by the thousands. This very different form of storytelling leaves pauper children but one role, that of innocent victims, while it simultaneously cries out for blame to be placed, elsewhere. 


\section{Notes}

1. This is a similar approach to that taken implicitly in Levene's collection of narratives from the London Foundling Hospital (which itself forms part of a wave of interest in plebeian autobiographical writing), but here is enriched by combination with doctors' voices and those of writers and parish officers.

2. Exceptions include those works exploring ailments of high society. See for example, Porter and Rousseau; Beatty.

3. 'Typhoid' Mary Mallon has become an ubiquitous public health story of the hazards of the asymptomatic disease vector. She infected dozens of people she encountered in her work as a domestic servant in the early years of the twentieth century (see Wald).

4. For a thoughtful critique of the different notions of patients and their histories and narratives see Condrau. 


\section{Works Cited}

A New Discovery of the Nature of the Plague. London, 1721.

Beatty, Heather. Nervous Disease in late Eighteenth-Century Britain. London: Pickering and Chatto, 2011.

Beier, A. L. Masterless Men: The Vagrancy Problem in England, 1560-1640. London: Routledge, 1985.

Bradwell, Steven. A Watchman for the Peste. London, 1625.

Buchan, William. Domestic Medicine; or, A Treatise on the Prevention and Cure of Diseases by Regimen and Simple Medicine: With Appendix Containing a Dispensatory. For the use of Private Practitioners. London: W. Strahan \& T. Cadell, 1781.

Cadogan, William. Essay upon Nursing and the Management of Children from their Birth to Three Years of Age. London: J. Roberts, 1748.

Champion, J. A. I. London's Dreaded Visitation: The Social Geography of the Great Plague of London, 1665. London: Centre for Metropolitan History, 1995.

Condrau, Flurin. “The Patient's View Meets the Clinical Gaze." Social History of Medicine 20.3 (2007): 525-40.

Coxe, Thomas. A Discourse wherein the Interest of the Patient in Reference to Physick and Physicians is Soberly Debated. London: C.R., 1669.

Defoe, Daniel. Due Preparations for the Plague. London, 1722.

Dunlap, Barbara. "The Problem of Syphilitic Children in Eighteenth-Century Britain and France." The Secret Malady: Venereal Disease in Eighteenth-Century Britain and France. Ed. Linda E. Merians. Lexington, KY: U of Kentucky P, 1996. 114-127.

Foucault, Michel, The Birth of the Clinic: An Archaeology of Medical Perception. New York: Pantheon, 1973.

Ellis, William. The Country Housewife's Family Companion. London, 1750.

Gilman, Sander, Helen King, Roy Porter, G. S. Rousseau, and Elaine Showalter. eds. Hysteria Beyond Freud. Berkeley: U of California P, 1993.

Gregory, John. Elements of the Practice of Physic. Edinburgh: W. Creech, 1788.

Hanway, Jonas. An Earnest Appeal for Mercy to the Children of the Poor. London 1766.

Harvey, Gideon. The Disease of London: or A New Discovery of the Scorvey. London: Printed by B. W. for W. Thackery, at the Angel in Duck-Lane, 1684.

Hodges, Nathaniel. Loimologia, or, An Historical Account of the Plague in 1665. London: Printed for E. Bell, and J. Osborn, 1720.

Houston, R. A. "Madness and Gender in the Long Eighteenth Century." Social History 27.3 (2002): 309-26.

Laqueur, Thomas. Making Sex: Body and Gender from the Greeks to Freud. Cambridge, Mass.: Harvard UP, 1992.

Lees, Lynn Hollen, The Solidarities of Strangers: the English Poor Laws and the People, 1700-1948. Cambridge: Cambridge UP, 1998.

Levene, Alysa. The Childhood of the Poor: Welfare in Eighteenth-Century London. Basingstoke: Palgrave Macmillan, 2012.

Levene, Alysa, Narratives of the Poor in Eighteenth-Century Britain. 5 vols. London: Pickering and Chatto, 2006.

Levene, Alysa, Thomas Nutt, and Samantha Williams, ed. Illegitimacy in Britain, 1720-1920. Basingstoke: Palgrave Macmillan, 2005. 
London Foundling Hospital Correspondence. MS. London Metropolitan Archive. London.

Mansey, Lewis. The Practical Physican. London: Printed by W. Stratford. For J. Stratford 1800.

Martensen, Robert. "The Transformation of Eve: Women's Bodies, Medicine and Culture in Early Modern England." Sexual Knowledge, Sexual Science: The History of Attitudes to Sexuality. Ed. Roy Porter and Mikulas Teich. Cambridge: Cambridge UP, 1994. 107-133.

Cheryl Mattingly and Linda C. Garro. "Narrative as Construct and Construction," Narrative and the Cultural Construction of Illness and Healing. Ed. Cheryl Mattingly and Linda C. Garro. Berkley: U of California P, 2000. 1-49.

Mead, Richard. A Short Discourse Concerning Pestilential Contagion. London: S. Buckley, 1720.

Müller-Wille, Staffan and Hans-Jörg Rheinberger, eds. Heredity Produced: At the Crossroads of Biology, Politics, and Culture, 1500-1870. MIT Press, 2007.

Newton, Hannah. The Sick Child in Early Modern England, 1580-1720. Oxford: Oxford UP, 2012.

P. L., A Letter from an Apothecary in London. London: M. Cooper, 1752.

Pringle, John. Observations on the Diseases of the Army. $5^{\text {th }}$ ed. London: A. Millar, D. Wilson and T. Durham and T. Payne, 1765.

Porter, Roy and G. S. Rousseau. Gout: Patrician Malady. New Haven: Yale U $\mathrm{P}, 1998$.

Pugliatti, Paula. Beggary and Theatre in Early Modern England. Aldershot: Ashgate, 2003.

Risse, Guenter. New Medical Challenges during the Scottish Enlightenment, Amsterdam: Rodopi, 2005.

St Botolph Aldgate Guardians' Visiting Book. MS. Guildhall Library, London.

St Dunstan in the West Committee of the Guardians of Poor Children. MS. Guildhall Library, London.

St Sepulchre Holborn Minutes of the Meetings of the Guardians of the Parish Poor. MS.Guildhall Library, London.

Stewart, Mary Margaret. "And Blights with Plagues the Marriage Hearse: Syphilis and Wives." The Secret Malady: Venereal Disease in Eighteenth-Century Britain and France. Ed. Linda E. Merians. Lexington, KY: U of Kentucky P, 1996. 103-113.

Schiebinger, Londa. The Mind Has No Sex? Women in the Origins of Modern Science, Cambridge Mass.: Harvard UP, 1989.

Slack, Paul. The Impact of Plague in Tudor and Stuart England. Oxford: Oxford UP, 1985.

Spooner, Thomas. Short Account of the Itch. London: J. Roberts, and A. Dodd, 1728.

Stolberg, Michael. "A Woman Down to Her Bones: The Anatomy of Sexual Difference in the Sixteenth and Early Seventeenth Century." Isis 94 (2003): 274-299.

Wald, Priscilla. Contagious: Cultures, Carriers and the Outbreak Narrative. Durham, NC: Duke UP, 2008.

Ward, Candace. Desire and Disorder: Fevers, Fictions and Feelings in English Georgian Culture. Lewisberg, PA: Bucknell UP, 2007.

Wear, Andrew. Knowledge and Practice in English medicine, 1550-1680. Cambridge: Cambridge UP, 2000.

Willis, Thomas. Practice of Physick. London: T. Dring C. Harper \& J. Leigh, 1684. 